Tiempo Económico

Núm. 35, vol. XII

Primer cuatrimestre de 2017

\title{
LAS VARIACIONES EN EL TIPO DE CAMBIO EN MÉXICO Y SU IMPACTO EN LA CANASTA SALARIAL, 1993-2015
}

L. Carolina Hernández Calvario*

\section{Resumen}

Este trabajo tiene como objetivo analizar las variaciones del tipo de cambio en México y su impacto en la canasta salarial. El trabajo consta de cuatro apartados. En el primer apartado se realiza un breve análisis del comportamiento del tipo de cambio nominal y real y su impacto sobre el salario real. En el segundo apartado se tratan algunos conceptos clave como valor de la fuerza de trabajo y canasta salarial. Lo que da paso a analizar la composición de la canasta salarial en el país, en donde además se presentan consideraciones entorno a la diferencia en el comportamiento del INPC general y el INPC de la canasta salarial. En el tercer apartado se estudia el comportamiento de las importaciones totales y las importaciones de los bienes que integran la canasta salarial y, en el último apartado se centra en el impacto de la devaluación sobre las importaciones de la canasta salarial.

\section{Abstract}

This document aims to analyze the impact of changes in the exchange rate in Mexico and its impact on the wage basket. The work consists of $\mathrm{V}$ sections. In paragraph I a brief analysis of the behavior of the nominal and real exchange rates and their impact on real wages. In section II some key concepts as the value of the labor force and wage basket are treated. In section III the composition of the basket wage is analyzed, where further considerations around the difference in behavior of

* Profesora del Área de Economía Política. Departamento de Economía de la Universidad Autónoma Metropolitana-Unidad Iztapalapa. Correos: hernandezcalvarioc@xanum.unam.mx, hclc.unam@gmail. com 
the overall NPI and the NPI wage basket. In section IV behavior of total imports and imports of goods that make up the wage basket is studied and finally, section $\mathrm{V}$ focuses on the impact of devaluation on imports of the wage basket.

Palabras clave: Canasta de consumo salarial, depreciación del tipo de cambio, tasa de inflación.

Keywords: Consumer salary, depreciation of the exchange rate, inflation rate

\section{Introducción}

El presente trabajo va más allá de las contribuciones dirigidas a investigar el comportamiento del tipo de cambio y su impacto sobre la estructura de la demanda de las importaciones mexicanas. El análisis empírico aquí desarrollado tiene como propósito hacer un primer acercamiento al estudio del impacto devaluatorio de la moneda mexicana sobre las importaciones de los bienes que integran la canasta salarial. Creemos que esto contribuye al debate de la situación salarial en el país, que en años recientes pasó a cobrar relevancia.

La investigación se realiza con base en la elaboración de una línea coherente de las categorías marxistas. Ejemplo de ello es el tratamiento que se le da a uno de los conceptos clave de la Economía Política: el Valor de la Fuerza de Trabajo. Entendido como: El tiempo de trabajo necesario para producir la fuerza de trabajo viene a reducirse al tiempo necesario para la producción de estos medios de vida; o lo que es lo mismo, el valor de la fuerzas de trabajo es el valor de los medios de vida necesarios para asegurar la subsistencia de su poseedor. (Marx, El Capital, TI: 145)

En razón de lo cual, se hará una aproximación al análisis del consumo de los trabajadores mexicanos mediante la comparación de las canastas salariales alimentarias. La intención es dar cuenta de los cambios en cantidad y en precios de las mismas, derivados de la devaluación de peso mexicano con respecto al dólar, sobre las importaciones de 28 capítulos que forman parte de la canasta salarial.

\section{El comportamiento del tipo de cambio y su impacto en el salario real}

A partir de la autonomía del Banco Central mexicano, la política económica nacional, lejos de procurar el crecimiento económico y el pleno empleo en el país (pues dejaron de ser sus objetivos prioritarios), se ha encaminado a procurar la estabilidad en precios, tal y como sugiere la teoría neoliberal sintetizada en el Consenso de Washington. Sin embargo, de acuerdo con datos del Banco de México, en los años recientes (de enero de 1993 a enero de 2016), el peso mexicano ha registrado una depreciación de cerca del 70 por ciento con respecto al dólar estadounidense. Ante esta situación, las principales explicaciones encontradas por 
parte de instituciones oficiales, como son el Banco de México y el Centro de Estudios de las Finanzas Públicas de la Cámara de Diputados, se encuentran: 1) El fortalecimiento de la moneda estadounidense en aras de las expectativas de normalización de la política monetaria de Estados Unidos, y la divergencia de la política monetaria de Estados Unidos con respecto a otras potencias como Europa y Japón; 2) La caída de los mercados accionarios chinos y; 3) La caída en los precios del petróleo registrada en los años de estudio.

En lo que respecta al punto 1), encontramos que las expectativas se cumplieron el 16 de enero del 2015, cuando la Reserva Federal de los Estados Unidos (FED) hizo el anuncio del inicio del proceso de normalización en su política monetaria, con un incremento de 0.25 puntos porcentuales en su tasa de interés de referencia (Banxico, 2015). Con lo que la depreciación no sólo se mantuvo, sino que presentó un punto máximo el 22 enero del 2016 cuando el tipo de cambio alcanzó los 18.42 pesos por dólar. En cuanto al punto 2), el 24 de agosto de 2015 se hizo pública la peor caída en ocho años de la bolsa de valores china, el Índice Compuesto de Shanghai perdió 8.5 por ciento (CEFP, 2016). Por último, respecto al punto 3) tenemos que aún no se cumplen los pronósticos emitidos por los especialistas, quienes desde el año 2015 pronosticaban que los efectos de la caída en el precio del petróleo se percibirían desde el año 2016, cuando se esperaba que el precio del barril del petróleo se ubicara en los 49 dólares y no en los 76.40 dólares, como lo pronosticó la Secretaría de Hacienda y Crédito Público (SHCP) cuando realizó el contrato de las coberturas en 2015 (Pantaleón, 2016).

En una revisión del comportamiento del tipo de cambio pesos por dólar, se observa que en el periodo que comprende este análisis, la tendencia devaluatoria más profunda del tipo de cambio comenzó en 2014. Antes de este año, los meses con mayor depreciación fueron febrero y marzo de 2009 cuando el tipo de cambio registró los 14.59 y 14.66 pesos por dólar respectivamente. Si a esta revisión se le incluye el análisis del tipo de cambio real, entendido como la unidad de valor de la moneda en términos de su poder de compra (a pesos constantes de 1996), se observa que en el periodo de 1994 a 2015 se presentan tres periodos devaluatorios de la moneda mexicana: el primero en el periodo de 2003 al 2007 cuando se registra un alza en el tipo de cambio real que pasa de los 5.55 a los 6.22 pesos por dólar; el segundo en el año 2009 con respecto al año inmediato anterior, cuando se cambia de los 5.90 a los 6.82 pesos por dólar y; el tercero que comienza en 2013 al pasar de 6.02 a 7.34 pesos por dólar en el primer trimestre de 2016.

En la Gráfica 1 se muestra el comportamiento del tipo de cambio real y su relación con el salario mínimo real en México. Moreno Brid y Monroy (2015) mencionan que, a través de su impacto sobre el salario real, el tipo de cambio puede afectar la distribución factorial del ingreso, y de esta forma incidir en el peso y composición de la demanda interna sobre la actividad económica. Se observa una clara disminución del salario mínimo real en cerca de un 24.6 por ciento en el año 2015 con respecto a 1994, al pasar de los 78.84 a 59.41 pesos por día, respectivamente. Destaca el año 2009 no sólo por el hecho de registrar el valor 
mínimo del salario mínimo real al ubicarse en los 56.67 pesos por día, sino también porque esta reducción viene acompañada del incremento en el tipo de cambio real registrado en el mismo año. Si se compara este comportamiento con el que registra el salario medio en el país, ${ }^{1}$ se observa que del año 2002 al 2009 se presenta una reducción del salario medio del orden del 4.4 por ciento; y a partir de 2010 se observa un cambio en la tendencia; el salario medio promedia un crecimiento del 2.8 por ciento en el periodo de 2011 a 2015.

\section{Gráfica 1}

México: Comportamiento del tipo de cambio real y el salario mínimo

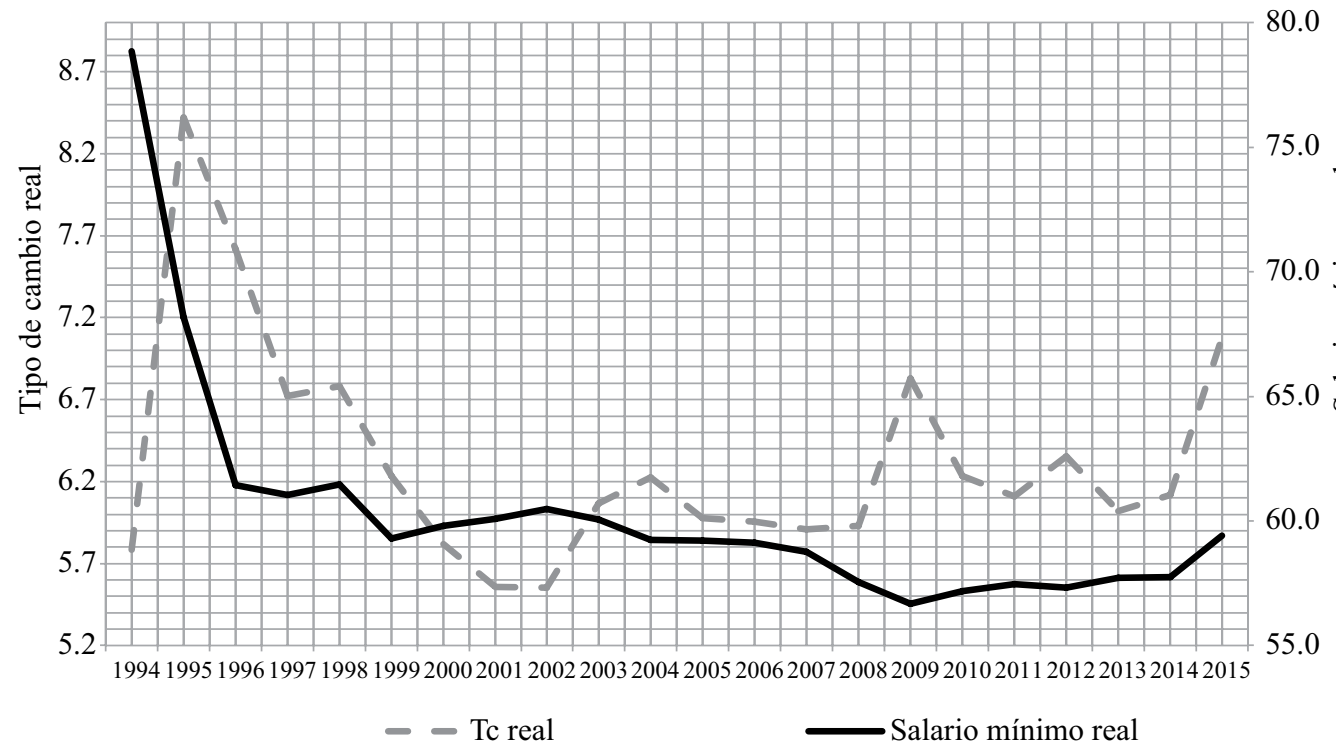

El tipo de cambio se calculó multiplicando el tipo de cambio nominal por la razón del índice de precios de Estados Unidos y México. El año base que se utiliza en este ejercicio es $1996=100$. El salario real se deflactó con el Índice Nacional de Precios al Consumidor para familias con ingresos de hasta un salario mínimo. El año base es la segunda quincena de diciembre de 2010.

Fuente: CEFP (2016) y CONASAMI (2016).

Dicho lo anterior, entramos al análisis del impacto de las variaciones del tipo de cambio sobre el consumo salarial, para lo cual es necesario tener claro algunos conceptos como salario y valor de la fuerza de trabajo.

1 El salario medio entendido como el importe de las retribuciones directas devengadas como promedio por un trabajador. 


\section{Conceptos clave para entender qué es la canasta salarial: Salario y valor de la fuerza de trabajo}

De acuerdo con datos de la Encuesta Nacional de Ocupación y Empleo (ENOE), entre 2005 y 2016 se registró en el país un crecimiento del número de personas bajo la relación de trabajo asalariado de cerca del 31.9 por ciento, al pasar de 24 millones 817 mil a 32 millones 730 mil personas en el primer trimestre de 2016. Si se compara la participación de los trabajadores asalariados con respecto al total de la población mexicana, se observa que en el año 2005 representaban el 23.2 por ciento y en 2016 pasaron a tener una participación del 26.9 por ciento, crecimiento que también se presenta al comparar el número de asalariados con respecto al número de población ocupada; se pasa del 59 al 64.5 por ciento en el mismo periodo. El crecimiento de la participación de los trabajadores asalariados se acompaña de la reducción de la participación de los empleadores que en 2005 representaron el 4.7 por ciento del total de la población ocupada y en el primer trimestre de 2016 el 4.4 por ciento, y de la reducción de los trabajadores por cuenta propia quienes cayeron del 23.7 al 22.4 por ciento de la población ocupada en el mismo periodo.

Cuadro 1

México: Comportamiento de la Población Ocupada y Asalariada, 2005-2016 (Número de personas y porcentajes de participación)

\begin{tabular}{|c|c|c|c|c|c|c|c|c|c|c|}
\hline \multirow[b]{2}{*}{ Año } & \multirow{2}{*}{$\begin{array}{c}\begin{array}{c}\text { Población } \\
\text { Total }\end{array} \\
\\
\text { Personas }\end{array}$} & \multicolumn{2}{|c|}{$\begin{array}{c}\text { Población } \\
\text { Económicamente Activa }\end{array}$} & \multicolumn{3}{|c|}{ Población Ocupada } & \multicolumn{4}{|c|}{ Trabajadores Asalariados } \\
\hline & & Personas & $\begin{array}{c}\% \\
\text { respecto } \\
\text { al total de } \\
\text { población }\end{array}$ & Personas & $\begin{array}{c}\% \\
\text { respecto } \\
\text { al total de } \\
\text { población }\end{array}$ & $\begin{array}{c}\% \\
\text { respecto } \\
\text { a la } P E A\end{array}$ & Personas & $\begin{array}{l}\text { \% respecto } \\
\text { al total de } \\
\text { población }\end{array}$ & $\begin{array}{c}\% \text { respecto } \\
\text { a la PEA }\end{array}$ & $\begin{array}{c}\% \\
\text { respecto a } \\
\text { población } \\
\text { ocupada }\end{array}$ \\
\hline 2005 & $107,155,784$ & $43,631,501$ & 40.7 & $42,079,136$ & 39.3 & 96.4 & $24,817,262$ & 23.2 & 56.9 & 59.0 \\
\hline 2006 & $108,416,556$ & $44,982,518$ & 41.5 & $43,378,461$ & 40.0 & 96.4 & $26,091,954$ & 24.1 & 58.0 & 60.1 \\
\hline 2007 & $109,795,643$ & $45,904,540$ & 41.8 & $44,231,248$ & 40.3 & 96.4 & $26,846,821$ & 24.5 & 58.5 & 60.7 \\
\hline 2008 & $111,304,405$ & $46,769,214$ & 42.0 & $44,943,527$ & 40.4 & 96.1 & $27,695,044$ & 24.9 & 59.2 & 61.6 \\
\hline 2009 & $112,849,217$ & $48,018,362$ & 42.5 & $45,435,352$ & 40.3 & 94.6 & $27,749,639$ & 24.6 & 57.8 & 61.1 \\
\hline 2010 & $114,291,638$ & $48,717,789$ & 42.6 & $46,121,621$ & 40.4 & 94.7 & $28,623,594$ & 25.0 & 58.8 & 62.1 \\
\hline 2011 & $115,684,856$ & $49,721,702$ & 43.0 & $47,138,887$ & 40.7 & 94.8 & $29,211,697$ & 25.3 & 58.8 & 62.0 \\
\hline 2012 & $117,055,022$ & $51,228,767$ & 43.8 & $48,706,734$ & 41.6 & 95.1 & $30,531,602$ & 26.1 & 59.6 & 62.7 \\
\hline 2013 & $118,396,855$ & $51,787,087$ & 43.7 & $49,227,313$ & 41.6 & 95.1 & $30,932,632$ & 26.1 & 59.7 & 62.8 \\
\hline 2014 & $119,714,945$ & $51,924,053$ & 43.4 & $49,415,412$ & 41.3 & 95.2 & $31,468,878$ & 26.3 & 60.6 & 63.7 \\
\hline 2015 & $121,007,187$ & $52,905,125$ & 43.7 & $50,611,332$ & 41.8 & 95.7 & $32,286,470$ & 26.7 & 61.0 & 63.8 \\
\hline 2016/01 & $121,803,321$ & $52,918,649$ & 43.4 & $50,778,629$ & 41.7 & 96.0 & $32,730,599$ & 26.9 & 61.9 & 64.5 \\
\hline
\end{tabular}

Fuente: Encuesta Nacional de Ocupación y Empleo, INEG (2016).

En una economía mercantil como es la capitalista, el salario se entiende como la expresión monetaria del valor de la fuerza de trabajo. La razón es que la fuerza de trabajo, como cualquier otra mercancía, se compra y se vende a un precio determinado, y el precio de esta peculiar mercancía se denomina salario. Las formas más comunes de medir el salario son: 1) Salario nominal, entendido como el precio en dinero del trabajo, es decir, como la suma 
de dinero por la que el trabajador vende su fuerza de trabajo. 2) Salario real, que refiere a la cantidad de mercancías que el trabajador puede comprar con el salario nominal, o lo que es lo mismo, la relación del precio de la fuerza de trabajo con respecto a las demás mercancías.

Con base en lo teorizado por Carlos Marx, diversos trabajos han abordado los factores que determinan el valor de la fuerza de trabajo. Por poner algunos ejemplos, tenemos a José Valenzuela y Jorge Isaac (1999), Diego Guerrero (2006). Estos autores desarrollan la idea de que la mercancía fuerza de trabajo, como cualquier otra, está determinada por el trabajo social que exige su producción. Dicho de otro modo, para que la fuerza de trabajo desempeñe sus funciones dentro del sistema de producción, es necesario que las personas consuman una determinada cantidad de bienes y servicios que deben ser comprados en el mercado, y el gasto realizado para su obtención depende del valor de los mismos; es decir, del tiempo de trabajo socialmente necesario que exige su producción. En palabras de Marx (1973:124), "el valor de la fuerza de trabajo es el valor de los medios de vida necesarios para asegurar la subsistencia de su poseedor."

Esto nos lleva a la definición de canasta salarial, entendida como el conjunto de bienes de consumo personal (valores de uso), que le permiten al trabajador reproducir su fuerza de trabajo. ${ }^{2}$ Para obtener el valor anual de la fuerza de trabajo, o valor anual de la canasta salarial, se multiplica la cantidad de bienes consumidos por los trabajadores por el precio de cada uno de ellos. ${ }^{3}$ Lo que nos lleva a tres importantes consideraciones: 1) La cantidad (o quantum) del consumo de los trabajadores puede aumentar sin que necesariamente se eleve el valor de la canasta salarial; puede darse el caso de que se presente una reducción en los valores unitarios de los bienes salarios que compense el mayor quantum. 2) Si para obtener el salario real se utiliza como ponderador el Índice Nacional de Precios al Consumidor (INPC), se debe tener claro que este índice refleja la composición del consumo de la familia media nacional, no en sí la composición de la canasta de consumo salarial. 3) Posibles modificaciones en la relación entre el comportamiento del tipo de cambio y la importación de los bienes que conforman la canasta salarial.

Para atender la consideración 1) se hará una comparación de las canastas salariales (alimentarias) que nos dé cuenta de los cambios tanto en cantidad (consumo por día de cada uno de los bienes) como de los precios (diarios y mensuales). Para atender la consideración 2), en

2 De acuerdo con INEGI la canasta salarial es un subconjunto de canastas de bienes y servicios del Índice de precios al consumidor Los bienes y servicios que actualmente conforman la canasta básica en México, fueron seleccionados por los representantes de los sectores firmantes del Pacto para la Estabilidad y el Crecimiento Económico (PACTO) a finales de 1988.

3 Por efecto de la disponibilidad de información, en este trabajo se tomarán los precios de los bienes consumidos por el trabajador, no así la cantidad de trabajo incorporados en su producción. Si el lector quiere profundizar en la relación entre valores y precios de producción, le sugerimos consultar los textos de Shaikh (1984) y Valle (1991), por mencionar algunos ejemplos. 
los cálculos que se realizan en este trabajo se utiliza el INPC de la canasta básica proporcionado por el Banco de México, en lugar el INPC general, pues a partir del año 2009 el índice de precios de la canasta básica crece más rápido que el de precios al consumidor general. Por último, en el punto 3) se analizará el impacto de la devaluación del peso mexicano con respecto al dólar sobre las importaciones de 28 capítulos que forman parte de la canasta salarial.

\section{Composición de la canasta salarial en México, 1992-2016}

La composición del gasto de consumo de los trabajadores está determinada en gran medida por su nivel de ingresos; cuando los niveles de ingreso son bajos, la mayor parte del gasto se destina a la compra de bienes básicos. Si se analiza el comportamiento del gasto en la canasta salarial dividido en alimentaria y no alimentaria, se puede observar que en las zonas urbanas (de mayor ingreso) el porcentaje del gasto destinado a bienes alimentarios es menor en comparación con el que se realiza en zonas rurales (de menor ingreso). De acuerdo con datos del Consejo Nacional de Evaluación de la Política de Desarrollo Social (CONEVAL), en el periodo que va de 1992-2016 el porcentaje promedio del gasto en alimentos de la canasta salarial urbana es de 45.1 por ciento, mientras que el dato en la canasta alimentaria rural es 50.6 por ciento. También se puede observar que 2002 es el año en el que ambas canastas salariales alimentarias registran un menor porcentaje con respecto al total del gasto en la canasta salarial total con un 41.7 y 46.9 por ciento en las zonas urbana y rural respectivamente; a su vez, 2016 es el año en el que mayor porcentaje del gasto alimentario se registra, con un 49.4 y 54.8 por ciento respectivamente. En ambos casos, el incremento de la proporción del gasto en alimentos en el periodo de 1992 a 2016 fue del 0.2 por ciento.

Cuando se analiza el precio de cada una de las canastas (urbana y rural) desglosadas en alimentaria y no alimentaria, se observa que la canasta salarial urbana en el periodo de 1992 a 2016 presenta una tasa de crecimiento de 639.1 por ciento, con un crecimiento de la canasta alimentaria del orden del 674.3 por ciento y de la canasta no alimentaria de 610.2 por ciento. Por su parte, la canasta salarial rural en el mismo periodo aumentó 706.1 por ciento, con un crecimiento en el precio de la canasta alimentaria y no alimentaria del orden del 735 y 673.6 por ciento respectivamente. En la Gráfica 2 se puede observar el comportamiento delo precios de cada una de las canastas.

La estructura de la canasta alimentaria también presenta modificaciones en el periodo que se viene estudiando. En el Cuadro 2 se muestran los bienes que conforman la canasta alimentaria urbana, que en el año 1992 estaba integrada por 33 bienes y veinticuatro años después la conforman 37 bienes. Entre los principales cambios que se observan, destaca la eliminación de bienes como maíz en grano y leche bronca (que se sustituye por entera y ligth), y la incorporación de bienes como pan para sándwich y hamburguesas, chorizo y longaniza, yogur y jugos y néctares. Como se mencionó anteriormente, el incremento en los precios de 
estos bienes fue del orden del 671.3 por ciento, al pasar de un precio de 174.14 pesos mensuales en febrero de 1992 a 1,343.22 pesos en 2016 del mismo mes de 2016.

\section{Gráfica 2}

México: Comportamiento de la canasta salarial, 1992-2016 (En pesos mexicanos constantes)

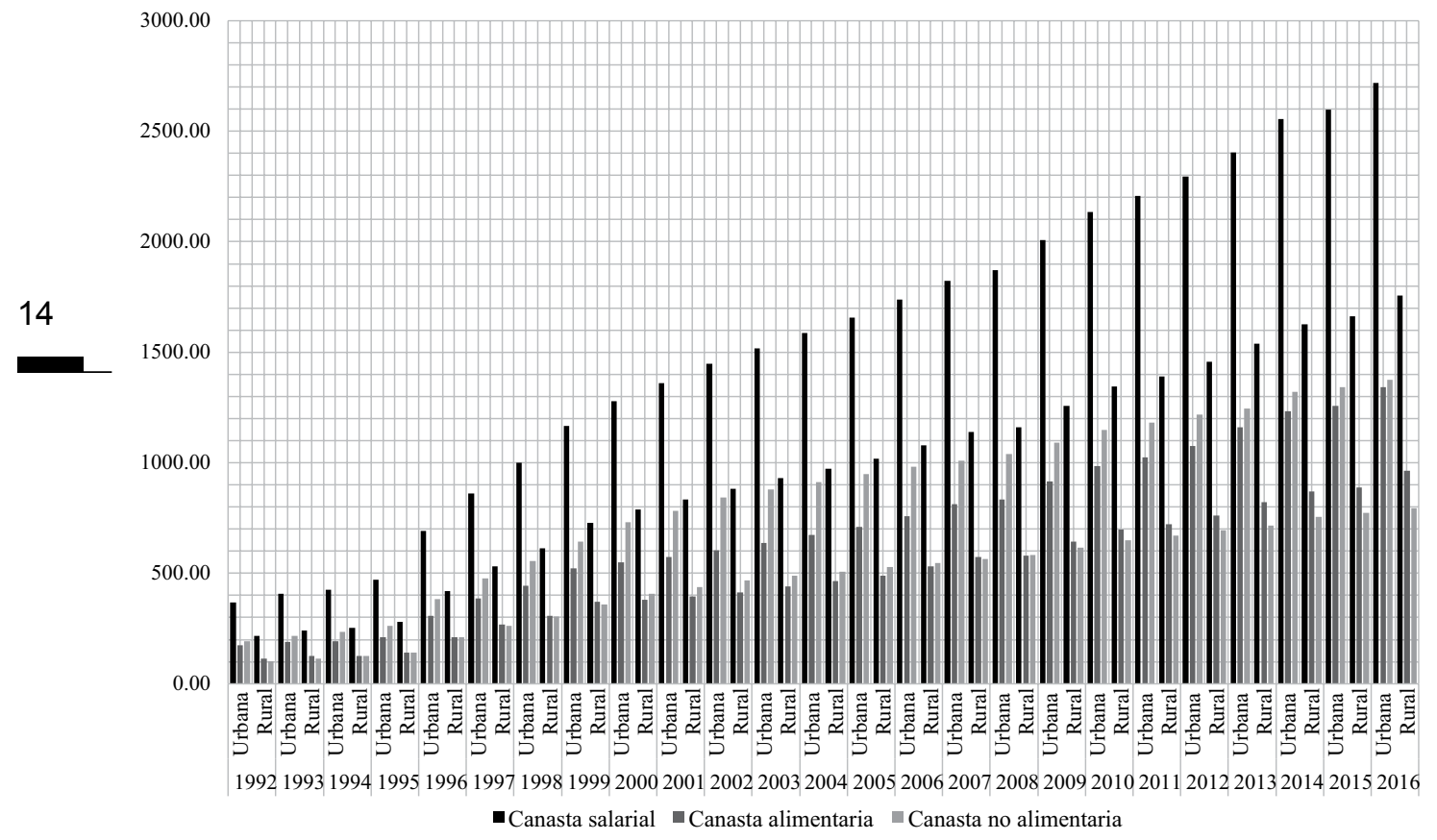

Notas: 1) Los datos que se presentan son del mes de febrero de cada año. 2) De acuerdo con INEGI, a partir de la primera quincena de abril de 2013 el INPC se calcula con nuevos ponderadores obtenidos de la ENIGH 2010. Fuente: CONEVAL (2016).

Por su parte, los rubros que conforman la canasta no alimentaria son: i) transporte público, ii) limpieza y cuidados de la casa, iii) cuidados personales, iv) educación, cultura y recreación, v) comunicaciones y servicios para vehículos, vi) vivienda y servicios de conservación, vii) prendas de vestir, calzado y accesorios, viii)cristalería, blancos y utensilios domésticos, ix) cuidados de la salud, $\mathrm{x}$ ) enseres domésticos y mantenimiento de la vivienda, xi) artículos de esparcimiento y xii) otros gastos. En el caso de las zonas rurales, en el año 1992 los rubros que más gasto representaron fueron el vii), el i) y el vi) con una participación de 9.28, 6.82 y 6.12 por ciento, respectivamente; para 2016 la composición cambió, cuando i) se colocó como el de mayor participación con un 7.74 por ciento, el rubro ix) se ubicó en segundo lugar con una participación de 6.85 por ciento y en tercer lugar tenemos el vi) con 6.74 por ciento. Por su parte, el rubro que en 1992 encabezó la canasta no alimentaria en zonas urbanas fue vii) con una participación de 8.65 por ciento, seguido de los rubros v) y i) con 7.45 y 7.22 
por ciento respectivamente; para 2016 con un 9.80 por ciento de participación, el rubro iv) encabeza la lista, seguido de i) y vi) con 8.21 y 7.70 por ciento, respectivamente.

Cuadro 2

Comparación de las canastas alimentarias urbanas de 1992-2016

\begin{tabular}{|c|c|c|c|c|c|c|c|c|c|c|c|}
\hline \multicolumn{6}{|c|}{$\begin{array}{l}\text { Precio de la canasta alimentaria urbana } \\
\text { al mes de febrero de } 2016\end{array}$} & \multicolumn{6}{|c|}{$\begin{array}{l}\text { Precio de la canasta alimentaria urbana } \\
\text { al mes de febrero de } 1992\end{array}$} \\
\hline & Producto & $\begin{array}{l}\text { Consumo } \\
\text { (gr x día) }\end{array}$ & $\begin{array}{l}\text { Precio } \\
\mathrm{x} \mathrm{kg} / \mathrm{L}\end{array}$ & $\begin{array}{l}\text { Costo } \\
\text { diario }\end{array}$ & $\begin{array}{l}\text { Costo } \\
\text { mensual }\end{array}$ & & Producto & $\begin{array}{l}\text { Consumo } \\
\text { (gr x día) }\end{array}$ & $\begin{array}{c}\text { Precio } \\
x \mathrm{~g} / \mathrm{L}\end{array}$ & $\begin{array}{l}\text { Costo } \\
\text { diario }\end{array}$ & $\begin{array}{l}\text { Costo } \\
\text { mensual }\end{array}$ \\
\hline 1 & Tortilla de maíz & 155.40 & 13.86 & 2.15 & 64.62 & 1 & $\begin{array}{l}\text { Maíz en } \\
\text { grano }\end{array}$ & 70.2 & 0.63 & 0.04 & 1.32 \\
\hline 2 & Pasta para sopa & 5.65 & 29.14 & 0.16 & 4.94 & 2 & $\begin{array}{l}\text { Tortilla de } \\
\text { maíz }\end{array}$ & 217.9 & 0.92 & 0.20 & 6.00 \\
\hline 3 & Pan blanco & 25.99 & 29.41 & 0.76 & 22.93 & 3 & $\begin{array}{l}\text { Pasta para } \\
\text { sopa }\end{array}$ & 7.8 & 4.04 & 0.03 & 0.95 \\
\hline 4 & Pan de dulce & 34.14 & 53.10 & 1.81 & 54.39 & 4 & $\begin{array}{l}\text { Galletas } \\
\text { dulces }\end{array}$ & 3.1 & 5.48 & 0.02 & 0.51 \\
\hline 5 & $\begin{array}{c}\text { Pan para } \\
\text { sándwich, } \\
\text { hamburguesas, }\end{array}$ & 5.57 & 47.46 & 0.26 & 7.93 & 5 & Pan blanco & 11.2 & 1.84 & 0.02 & 0.62 \\
\hline 6 & Arroz en grano & 9.23 & 17.40 & 0.16 & 4.82 & 6 & Pan de dulce & 18.0 & 4.11 & 0.07 & 2.22 \\
\hline 7 & $\begin{array}{l}\text { Cereal de maíz, } \\
\text { de trigo, de arroz, } \\
\text { de avena }\end{array}$ & 3.63 & 59.27 & 0.21 & 6.45 & 7 & $\begin{array}{l}\text { Arroz en } \\
\text { grano }\end{array}$ & 14.0 & 2.25 & 0.03 & 0.94 \\
\hline 8 & $\begin{array}{c}\text { Bistec: aguayón, } \\
\text { cuete, paloma, } \\
\text { pierna }\end{array}$ & 21.08 & 129.00 & 2.72 & 81.57 & 8 & $\begin{array}{l}\text { Bistec: } \\
\text { aguayón, } \\
\text { cuete, } \\
\text { paloma, } \\
\text { pierna }\end{array}$ & 18.5 & 15.27 & 0.28 & 8.49 \\
\hline 9 & Molida & 13.90 & 111.01 & 1.54 & 46.28 & 9 & $\begin{array}{l}\text { Cocido o } \\
\text { retazo con } \\
\text { hueso }\end{array}$ & 14.8 & 7.75 & 0.11 & 3.44 \\
\hline 10 & Costilla y chuleta & 20.28 & 73.09 & 1.48 & 44.47 & 10 & Molida & 13.6 & 14.42 & 0.20 & 5.89 \\
\hline 11 & $\begin{array}{l}\text { Chorizo y } \\
\text { longaniza }\end{array}$ & 3.13 & 85.16 & 0.27 & 7.99 & 11 & $\begin{array}{l}\text { Pierna, muslo } \\
\text { y pechuga } \\
\text { con hueso }\end{array}$ & 27.9 & 8.23 & 0.23 & 6.88 \\
\hline 12 & Jamón & 4.10 & 82.33 & 0.34 & 10.13 & 12 & $\begin{array}{l}\text { Pollo entero o } \\
\text { en piezas }\end{array}$ & 32.5 & 7.71 & 0.25 & 7.50 \\
\hline 13 & $\begin{array}{c}\text { Pierna, muslo } \\
\text { y pechuga con } \\
\text { hueso }\end{array}$ & 15.76 & 53.01 & 0.84 & 25.06 & 13 & $\begin{array}{l}\text { Pescado } \\
\text { entero }\end{array}$ & 6.3 & 5.35 & 0.03 & 1.01 \\
\hline 14 & $\begin{array}{l}\text { Pierna, muslo } \\
\text { y pechuga sin } \\
\text { hueso }\end{array}$ & 4.54 & 73.39 & 0.33 & 10.00 & 14 & $\begin{array}{c}\text { De vaca, } \\
\text { pasteurizada, } \\
\text { entera, light }\end{array}$ & 119.0 & 1.82 & 0.22 & 6.50 \\
\hline 15 & $\begin{array}{l}\text { Pollo entero o en } \\
\text { piezas }\end{array}$ & 17.07 & 47.71 & 0.81 & 24.43 & 15 & Leche bronca & 37.0 & 0.98 & 0.04 & 1.09 \\
\hline 16 & Pescado entero & 3.41 & 58.08 & 0.20 & 5.95 & 16 & Fresco & 5.0 & 9.00 & 0.04 & 1.34 \\
\hline 17 & $\begin{array}{l}\text { De vaca, } \\
\text { pasteurizada, } \\
\text { entera, light }\end{array}$ & 203.85 & 14.39 & 2.93 & 88.03 & 17 & De gallina & 29.6 & 3.30 & 0.10 & 2.93 \\
\hline 18 & Fresco & 4.84 & 69.17 & 0.33 & 10.05 & 18 & $\begin{array}{l}\text { Aceite } \\
\text { vegetal }\end{array}$ & 17.6 & 3.03 & 0.05 & 1.60 \\
\hline
\end{tabular}




\begin{tabular}{|c|c|c|c|c|c|c|c|c|c|c|c|}
\hline \multicolumn{6}{|c|}{$\begin{array}{l}\text { Precio de la canasta alimentaria urbana } \\
\text { al mes de febrero de } 2016\end{array}$} & \multicolumn{6}{|c|}{$\begin{array}{l}\text { Precio de la canasta alimentaria urbana } \\
\text { al mes de febrero de } 1992\end{array}$} \\
\hline & Producto & $\begin{array}{l}\text { Consumo } \\
\text { (gr } \times \text { día) }\end{array}$ & $\begin{array}{l}\text { Precio } \\
\mathrm{x} \mathrm{kg} / \mathrm{L}\end{array}$ & $\begin{array}{l}\text { Costo } \\
\text { diario }\end{array}$ & $\begin{array}{l}\text { Costo } \\
\text { mensual }\end{array}$ & & Producto & $\begin{array}{l}\text { Consumo } \\
\text { (gr x día) }\end{array}$ & $\begin{array}{l}\text { Precio } \\
\mathrm{xg} / \mathrm{L}\end{array}$ & $\begin{array}{l}\text { Costo } \\
\text { diario }\end{array}$ & $\begin{array}{l}\text { Costo } \\
\text { mensual }\end{array}$ \\
\hline 19 & Yogur & 6.67 & 32.36 & 0.22 & 6.48 & 19 & Papa & 32.7 & 1.94 & 0.06 & 1.90 \\
\hline 20 & De gallina & 33.36 & 27.88 & 0.93 & 27.90 & 20 & Cebolla & 39.4 & 1.63 & 0.06 & 1.93 \\
\hline 21 & Aceite vegetal & 10.89 & 23.20 & 0.25 & 7.58 & 21 & Chile* & 10.5 & 5.64 & 0.06 & 1.78 \\
\hline 22 & Papa & 44.64 & 13.08 & 0.58 & 17.52 & 22 & Jitomate & 67.1 & 2.59 & 0.17 & 5.21 \\
\hline 23 & Cebolla & 42.30 & 35.12 & 1.49 & 44.57 & 23 & Frijol & 63.7 & 2.54 & 0.16 & 4.86 \\
\hline 24 & Chile* & 10.17 & 46.58 & 0.47 & 14.21 & 24 & Limón & 22.4 & 2.26 & 0.05 & 1.52 \\
\hline 25 & Jitomate & 62.99 & 25.03 & 1.58 & 47.29 & 25 & $\begin{array}{l}\text { Manzana y } \\
\text { perón }\end{array}$ & 25.8 & 2.40 & 0.06 & 1.86 \\
\hline 26 & Frijol & 50.55 & 22.03 & 1.11 & 33.41 & 26 & Naranja & 24.8 & 0.82 & 0.02 & 0.61 \\
\hline 27 & Limón & 25.99 & 15.92 & 0.41 & 12.42 & 27 & $\begin{array}{l}\text { Plátano } \\
\text { tabasco }\end{array}$ & 32.5 & 1.52 & 0.05 & 1.48 \\
\hline 28 & Manzana y perón & 29.86 & 24.03 & 0.72 & 21.53 & 28 & Azúcar & 20.0 & 1.83 & 0.04 & 1.10 \\
\hline 29 & Naranja & 28.64 & 5.64 & 0.16 & 4.84 & 29 & $\begin{array}{l}\text { Pollo } \\
\text { rostizado }\end{array}$ & 3.5 & 10.62 & 0.04 & 1.10 \\
\hline 30 & Plátano tabasco & 34.65 & 14.52 & 0.50 & 15.09 & 30 & $\begin{array}{c}\text { Agua } \\
\text { embotellada }\end{array}$ & 241.8 & 0.14 & 0.03 & 1.04 \\
\hline 31 & Azúcar & 15.05 & 18.14 & 0.27 & 8.19 & 31 & $\begin{array}{l}\text { Refrescos } \\
\text { de cola y de } \\
\text { sabores }\end{array}$ & 106.2 & 1.19 & 0.13 & 3.79 \\
\hline 32 & Pollo rostizado & 8.66 & 76.64 & 0.66 & 19.91 & 32 & $\begin{array}{l}\text { Alimentos } \\
\text { y bebidas } \\
\text { consumidas } \\
\text { fuera del } \\
\text { hogar }\end{array}$ & & 5.55 & 18.28 & 548.46 \\
\hline 33 & $\begin{array}{l}\text { Agua } \\
\text { embotellada }\end{array}$ & 411.46 & 1.37 & 0.56 & 16.92 & 33 & $\begin{array}{c}\text { Otros } \\
\text { alimentos } \\
\text { preparados }\end{array}$ & & 10.37 & 6.78 & 203.40 \\
\hline 34 & $\begin{array}{l}\text { Jugos y néctares } \\
\text { envasados }\end{array}$ & 56.06 & 16.81 & 0.94 & 28.27 & & & & & & \\
\hline 35 & $\begin{array}{l}\text { Refrescos de cola } \\
\text { y de sabores }\end{array}$ & 168.99 & 11.71 & 1.98 & 59.35 & & & & & & \\
\hline 36 & $\begin{array}{c}\text { Alimentos } \\
\text { y bebidas } \\
\text { consumidas fuera } \\
\text { del hogar }\end{array}$ & & 1.55 & 12.25 & 367.51 & & & & & & \\
\hline 37 & $\begin{array}{l}\text { Otros alimentos } \\
\text { preparados }\end{array}$ & & 1.55 & 2.34 & 70.20 & & & & & & \\
\hline
\end{tabular}

Fuente: CONEVAL (2016).

Con los datos anteriores se pueden constatar cambios tanto en el tipo de bienes que conforman la canasta salarial, como en el precio de los mismos. Sin duda, ambas variaciones afectan el valor de la fuerza de trabajo en México, pues como se dijo anteriormente siguiendo a Marx (1973:124), "el valor de la fuerza de trabajo es el valor de los medios de vida necesarios 
para asegurar la subsistencia de su poseedor”. Para operacionalizar esta categoría, podemos recurrir a la expresión utilizada por Valenzuela e Isaac (1999), que recoge los dos elementos que determinan el valor de una masa de mercancía: su cantidad y el nivel de productividad (el inverso del costo unitario). Por un lado, la cantidad está expresada en el salario real $\left(\frac{S n}{(I N P C)}\right), \mathrm{y}$ por el otro, los niveles de la productividad expresada en F2. En términos formales tenemos:

$$
V f t=\frac{S n}{\left(F_{2}\right)(I N P C)}
$$

Dónde: $\mathrm{Vft}=$ valor de la fuerza de trabajo; $\mathrm{Sn}=$ salario nominal; $\mathrm{F}_{2}=$ productividad del trabajo en sector de bienes-salario; INPC $=$ nivel de precios de bienes de consumo.

La razón de utilizar esta fórmula y no la ya conocida $V f t=\frac{S n}{I N P C}$, es que le damos al indicador la cualidad de ser una magnitud variable, no así constante, al incorporar en su cálculo un indicador del desarrollo de las fuerzas productivas existentes. Para ello nos valemos de la siguiente cita: "Si se comparan los salarios o valores del trabajo normales en distintos países y en distintas épocas históricas dentro del mismo país, se ve que el valor del trabajo no es, por sí mismo, una magnitud constante, sino variable, aun suponiendo que los valores de las demás mercancías permanezcan fijos.” (Marx, 1873:228)

Dicho lo anterior, como en el denominador se ubica el nivel de precios y éste ha crecido, sólo un aumento proporcional en los niveles de productividad, o un incremento del salario nominal podrían evitar que el precio del trabajo descendiera por debajo del valor de la fuerza de trabajo, y con ello los asalariados mexicanos no vieran afectado su nivel de vida. Ahora bien, si queremos profundizar en el análisis del impacto del INPC sobre el valor de la fuerza de trabajo, resulta útil plantear dos escenarios: 1) se puede dar el caso en el que el INPC aumente más rápido que el índice de precios adecuado al consumo salarial. Este escenario provocaría que el salario real efectivo fuera superior a la estimación usual. 2) Puede darse el caso de que el INPC aumente menos rápido que el índice adecuado al consumo salarial. En cuyo caso, el salario real efectivo va a ser menor al calculado estadísticamente.

De acuerdo con datos publicados por el CONEVAL y la UNICEF, en México se presenta el escenario 2): "Durante 2008 y 2009 el aumento del precio de los alimentos fue superior al de la inflación general. Asimismo, en 2009 el valor de la canasta alimentaria (...) aumentó $10.5 \%$, el doble del incremento en el Índice Nacional de Precios al Consumidor (INPC), que fue de 5.3\%". (CONEVAL y UNICEF, 2013:2). Esto se sostiene cuando se realiza el comparativo ente los dos INPC, pues el crecimiento promedio del INPC de la canasta básica en el periodo 1992-2016 es de 786.7 por ciento y el del INPC general es de 661.09 por ciento en el mismo periodo; es decir, que la variación de los precios medidos con el INPC general es 26 por ciento menor que la registrada en el INPC de la canasta básica. 


\section{Comportamiento de las importaciones totales y de las importaciones que integran la canasta salarial}

En esta sección se tiene como propósito calcular el impacto de las importaciones en el valor de la canasta salarial, en consecuencia, en el valor de la fuerza de trabajo. Se parte del supuesto de que en el actual patrón de acumulación (llamado neoliberal), la cantidad de bienes de consumo importados que adquieren los trabajadores es mayor que la registrada en el patrón de industrialización sustitutivo de importaciones. ${ }^{4}$ Para desarrollar este planteamiento es necesario hacer las siguientes consideraciones: 1) En el periodo de va de 2005 a 2015 (tomando como base el primer trimestre del año 2005), el crecimiento promedio del volumen total de las exportaciones fue de 1.81 por ciento, mientras que el de las importaciones totales fue de 0.93 por ciento. 2) Como consecuencia de la crisis mundial que tuvo comienzo en 2008, a partir del cuarto trimestre de ese año, se presenta una caída del índice de ocupación en el sector manufacturero, llegando a alcanzar en el segundo trimestre del 2009 su punto más bajo, al caer 5.14 por ciento respecto al mes de enero del 2005. 3) Derivado del punto anterior, se presenta una importante caída en el primer trimestre de 2009 del índice exportaciones que pasa de 130.56 a 111.73, pese a que las importaciones mantendrán un comportamiento creciente hasta entrado el tercer trimestre del año 2010. 4) De acuerdo con los datos del Cuadro 3, la productividad promedio de las exportaciones totales en el periodo de 2005 a 2015 fue de 1.39. El capítulo correspondiente a vehículos terrestres y sus partes es el que presenta una mayor productividad con un índice promedio de 1.82 y el que menor productividad registra es el capítulo que refiere a aparatos mecánicos, calderas y sus partes, con una productividad de1.30.

Se tomó como trabajo aplicado el índice de ocupación del sector manufacturero ya que las exportaciones más dinámicas de México se ubican en este sector. Las ramas con mayor relevancia son: 1) maquinaria y material eléctrico, 2) vehículos terrestres y sus partes, 3) aparatos mecánicos, calderas y sus partes, 4) instrumentos y aparatos de óptica y médicos y 5) combustibles minerales y sus productos. Estas ramas representan el 69.8 por ciento del total de las exportaciones en el periodo que va del primer trimestre de 1993 al primer trimestre de 2016.

4 Según la Unidad de Evaluación y Control de la Cámara de Diputados (UEC), en el año 2012 "la compra de alimentos básicos del exterior es de 45 por ciento de lo que se consume." Tomado de La Jornada, $21 / 04 / 2014$. 
LAS VARIACIONES EN EL TIPO DE CAMBIO EN MÉXICO Y SU IMPACTO EN LA CANASTA SALARIAL, 1993-2015

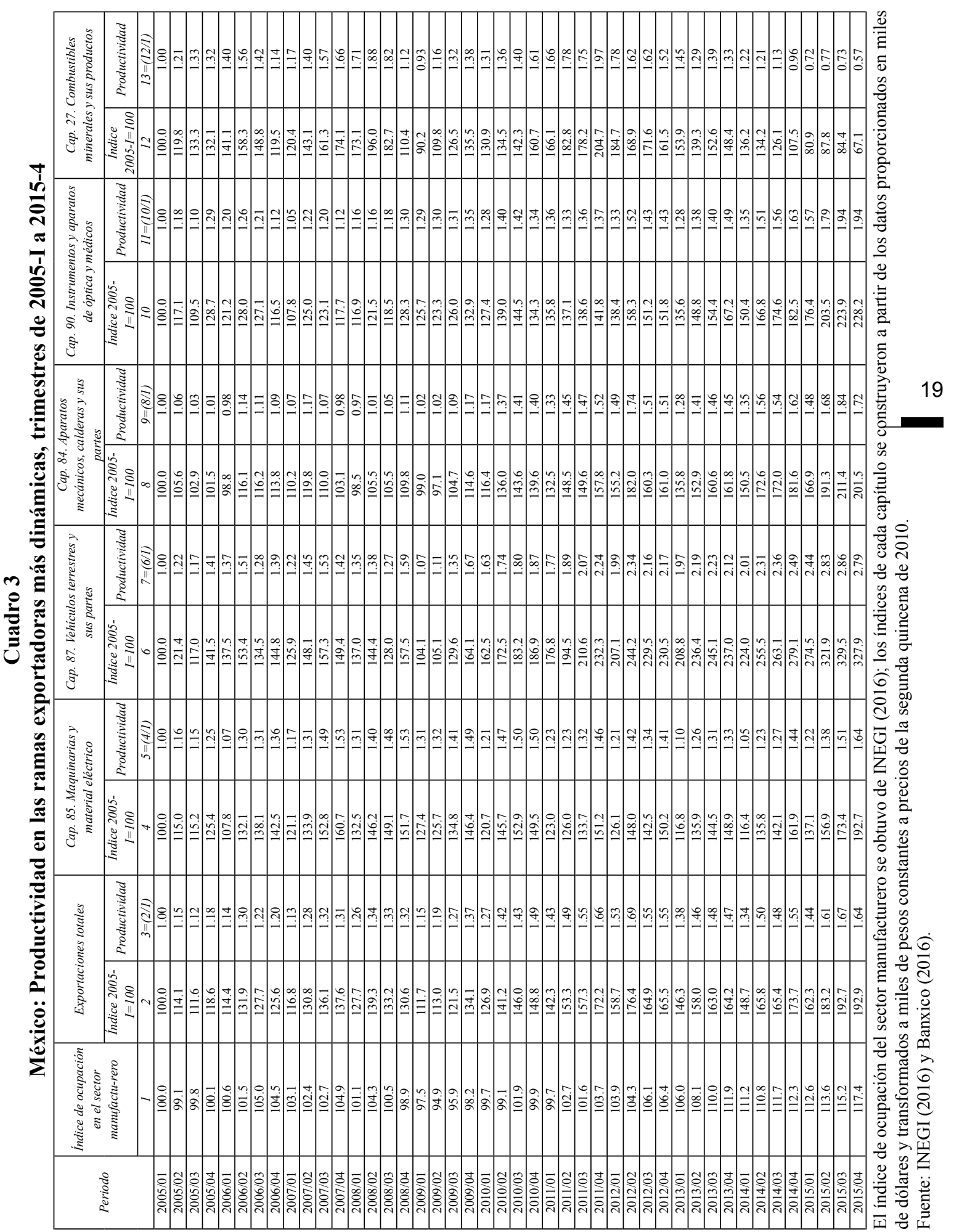




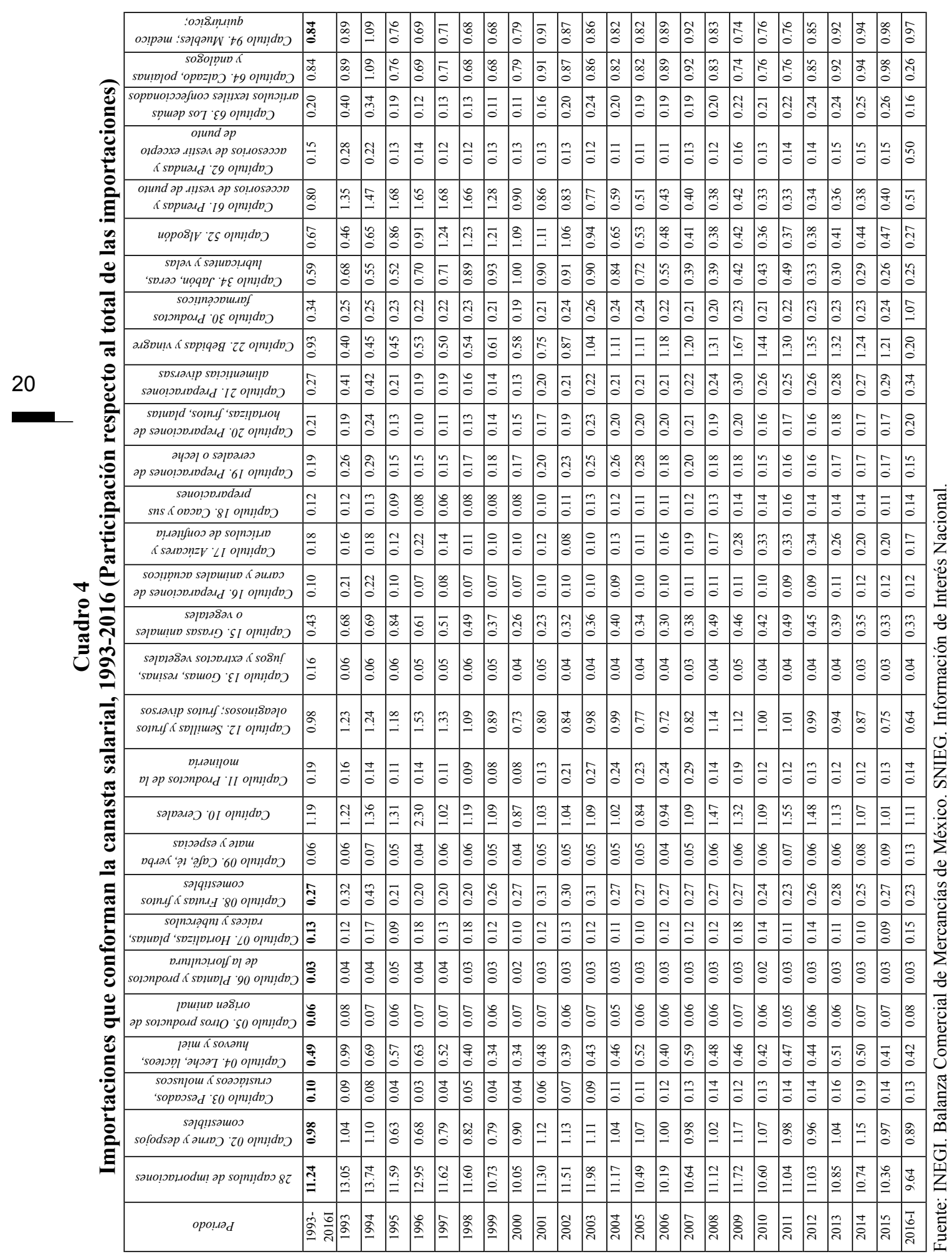




\section{Impacto de la devaluación sobre las importaciones de la canasta salarial}

En la Gráfica 3 llama la atención la reducción en el total de las importaciones (medidas en unidades monetarias) después de dos periodos devaluatorios: 1) el que se presenta después de la crisis de 2008 y 2) el que se observa de octubre de 2015 a enero de 2016 . Respecto al inciso 1), se observa que en los meses de agosto de 2008 a marzo de 2009 el tipo de cambio registra un aumento consecutivo al pasar de los 10.11 a los 14.67 pesos por dólar. Situación que se acompaña de una reducción en el total de las importaciones que pasan de los 3,201,342 miles de pesos en agosto de 2008 a 2,920,296 miles de pesos en el mismo periodo. Es decir, que estamos hablando de un aumento en el tipo de cambio nominal del orden del 45 por ciento, seguido de una disminución de las importaciones (medidas en miles de pesos reales a precios del primer trimestre de 2005) de cerca de 18 por ciento.

Respecto al inciso 2), tenemos que el promedio de las importaciones en el periodo que va de enero de 1993 a enero de 2016 es de 2, 616,546 miles de pesos; el mayor nivel de importación se presenta en el mes de octubre el 2015 con un total de 4, 891,546 miles de pesos, equivalente a 1.87 veces más que el promedio registrado en el periodo. Si comparamos el crecimiento de las importaciones del mes de enero de 2016 (último mes del cual se tiene datos) con respecto al mes de octubre de 2015 se observa una caída del orden del 15.9 por ciento, que a su vez se acompaña de un aumento del tipo de cambio de poco más del 9 por ciento; la tendencia fue en aumento si se considera que en los meses consecutivos, el tipo de cambio nominal llegó a alcanzar los 20 pesos por dólar.

\section{Gráfica 3}

México: Comportamiento de las importaciones totales y el tipo de cambio, 1993-I a 2016-I

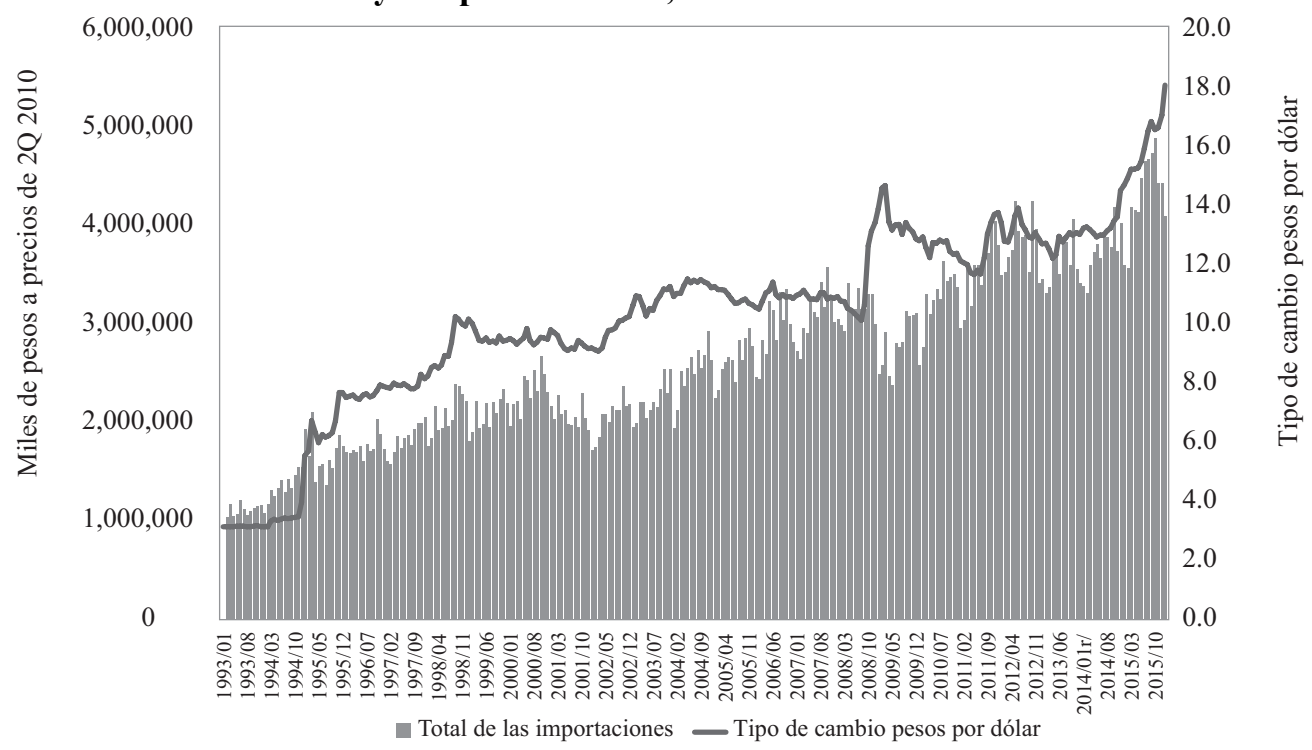

Fuente: BANXICO (2016) e inegi. Balanza Comercial de Mercancías de México (2016). 
Si se analiza el comportamiento del tipo de cambio pesos por dólar y las importaciones de bienes que conforman la canasta salarial (MBCS), ${ }^{5}$ se observa que el promedio de las MBCS en el periodo de enero de 1993 a enero de 2016 es de 277,331 miles de pesos constantes a precios de la segunda quincena de 2010. El mes de septiembre de 2015 es cuando se registran los mayores niveles de importaciones, con un valor de cerca de 474,074 miles de pesos. Sin embargo, también se observa que pese a este aumento en la cantidad de importaciones (medidas en términos reales a precios constantes de la segunda quincena del año 2010), la participación de las MBCS con respecto al total de las importaciones registra un comportamiento a la baja, tal y como se puede ver con la línea de tendencia en la Gráfica 4. La mayor participación de las MBCS con respecto al total de las importaciones se da en el mes de diciembre de 1994, con 14.35 por ciento del total de las importaciones, dato que contrasta con el 9.64 por ciento que se presenta en enero del 2016.

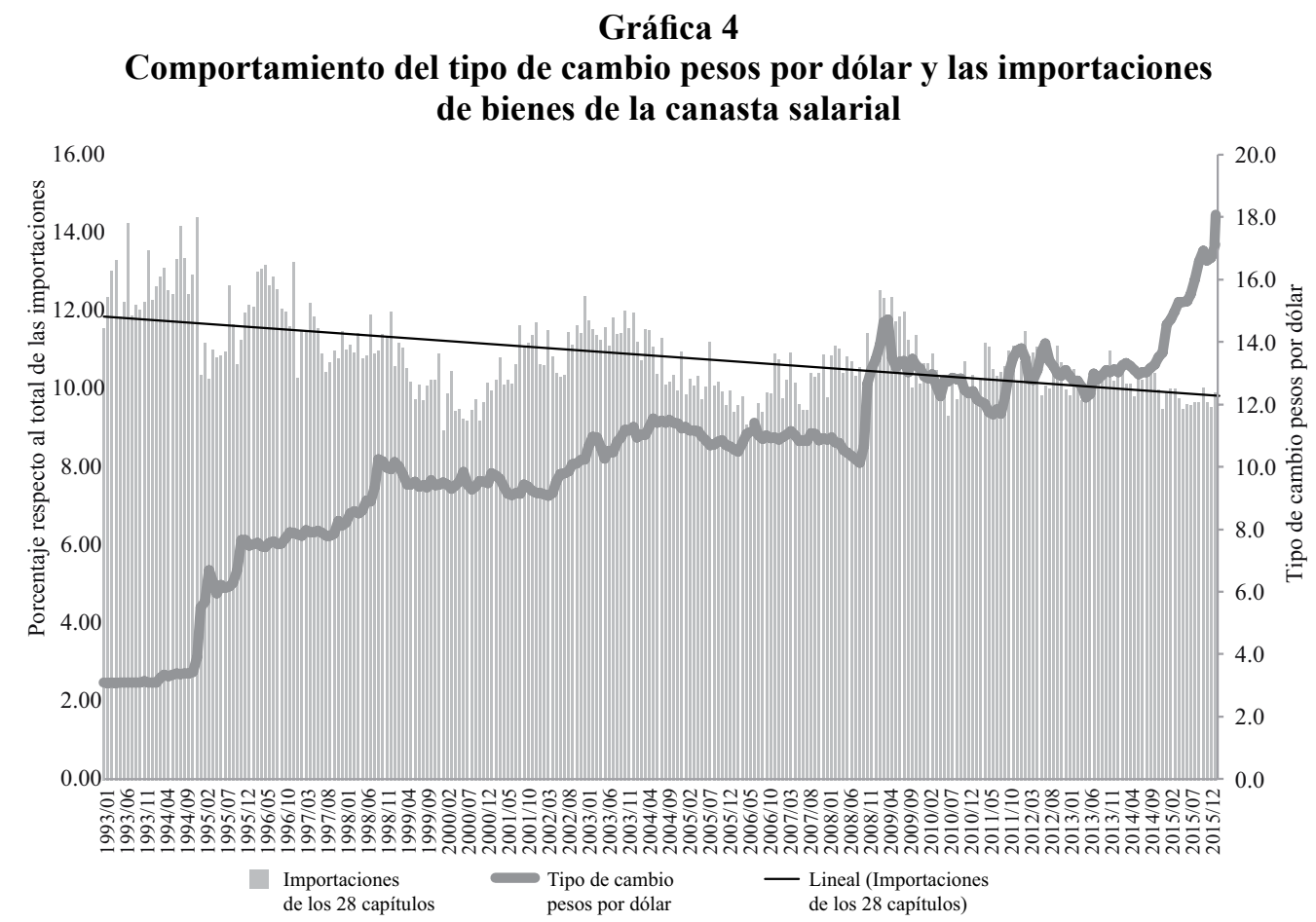

El tipo de cambio refiere al utilizado para solventar obligaciones denominadas en moneda extranjera, Fecha de determinación (FIX) Cotizaciones promedio.

Fuente: BANXICO, INEGI. Balanza Comercial de Mercancías de México. SNIEG. Información de Interés Nacional.

5 En razón de que las importaciones están medidas en pesos reales, el impacto de los precios en las cantidades se reduce, haciendo que el dato permita acercarnos a la cantidad de importaciones. 
A diferencia del comportamiento observado en el periodo de 2008 y 2009 entre el tipo de cambio y las importaciones totales, en donde se ve una disminución en el valor monetario de las importaciones como consecuencia de una depreciación del peso mexicano con respecto al dólar, se puede ver que la participación de la MBCS más que disminuir, aumentó al pasar de un 10.03 por ciento con respecto al total de las importaciones en septiembre de 2008 a un 12.32 por ciento en abril de 2009. No ocurre lo mismo en los meses de octubre de 2015 a enero de 2016, en donde la participación no llega ni al 10 por ciento, como parte de la tendencia a la baja que se registra en el indicador.

De esta situación se pueden desprender tres hipótesis: 1) Se ha dado una disminución en el precio internacional de los bienes importados que conforman la canasta salarial mexicana, lo que provoca una disminución en el precio de las importaciones, más no su cantidad; 2) La economía mexicana muestra una disminución en la capacidad para generar las divisas que permitan mantener el nivel de las importaciones, con lo cual las importaciones de la canasta salarial han disminuido en volumen. Se presenta una reducción de la productividad indirecta de las importaciones mexicanas. Esto si consideramos que el promedio de la deuda total del sector público en el periodo de 2009 a 2015 registra un aumento del orden del 21.9 por ciento, destacando el año 2009 cuando el incremento fue del orden del 78 por ciento al pasar de 1,780 miles de millones de pesos a 3,169 miles de millones de pesos. Por su parte, las reservas internacionales en el periodo de 2009 a 2015 registran una tasa de crecimiento del 4.3 por ciento, y una variación del 0.7 por ciento en el primer trimestre de 2015 , rondando para este periodo los 6,215,533 miles de dólares. 3) Estamos ante la presencia de una política económica que busca contener la devaluación de la moneda mexicana, por la vía de una reducción en el nivel de importación de algunos productos, entre los que se encuentran lo que conforman la canasta salarial mexicana.

Aproximándonos al análisis del inciso 1) podemos ver cómo el Índice de Precios al Productor (PPI, por sus siglas en ingles) de Estados Unidos, el principal socio comercial de México (con cerca de un 80 por ciento del comercio del país), en lo que va del 2015 y 2016 no presenta una mayor diminución. Lo mismo ocurre con su tasa de inflación, la cual en lo que va de 2016 promedia 1.157 por ciento. Por lo que con estos datos no se explicaría el fenómeno de la disminución de las importaciones de bienes de la canasta salarial mexicana. Para atender el inciso 2), debemos entender al sector exportador como el productor indirecto de los bienes que el país importa, al ser el generador de divisas que permiten llevar a cabo las compras de bienes importados. Dicho lo anterior, podemos suponer que el trabajo que se realiza en las actividades destinadas a la exportación es el que produce (indirectamente) los bienes importados del país. En este sentido, resulta necesario calcular la productividad "indirecta" que nos ayude a estimar el monto de importaciones que logra el país por unidad de trabajo gastada en el sector exportador. En términos formales tenemos: 


$$
\begin{aligned}
& F_{x, m}=\frac{Q m}{T x} \\
& Q x=(T x)(F x)
\end{aligned}
$$

Donde: $Q m=$ volumen (quantum) de importaciones; $T x=$ trabajo total aplicado en el sector exportador; $Q x=$ volumen (quantum) de exportaciones; $F x=Q x / T x=$ productividad en sector exportador.

El coeficiente Fm,x, lo hemos entendido como una productividad peculiar, que indica la capacidad del trabajo aplicado en el sector exportador para generar importaciones. Se puede observar que este indicador depende en gran medida de la productividad en las industrias que generan los productos que el país importa; si la productividad se eleva, caen los valores unitarios, y, por lo mismo, en igualdad de otras circunstancias, la capacidad importadora del país se elevará.

\section{Cuadro 5}

México: Cálculo de la productividad indirecta de las importaciones, datos

\begin{tabular}{|c|c|c|c|c|c|c|}
\hline \multirow{3}{*}{ Periodo } & \multirow{2}{*}{$\begin{array}{c}\text { Índice de ocupación } \\
\text { en el sector } \\
\text { manufacturero }\end{array}$} & Exportaciones totales & Importaciones totales & $F x$ & $F x, m$ & $Q x$ \\
\hline & & $\begin{array}{c}\text { Índice del volumen en } \\
\text { miles de pesos }\end{array}$ & $\begin{array}{c}\text { Índice del volumen en } \\
\text { miles de pesos }\end{array}$ & $Q x / T x$ & $Q m / T x$ & $(T x)(F x)$ \\
\hline & 1 & 2 & 3 & $4=2 / 1$ & $5=3 / 1$ & $6=((1)(4)) / 100$ \\
\hline $2005 / 01$ & 100.00 & 100.00 & 100 & 1.00 & 1.00 & 1.00 \\
\hline $2005 / 02$ & 99.15 & 114.07 & 105.08 & 1.15 & 1.06 & 1.14 \\
\hline $2005 / 03$ & 99.82 & 111.60 & 109.73 & 1.12 & 1.10 & 1.12 \\
\hline $2005 / 04$ & 100.13 & 118.57 & 111.04 & 1.18 & 1.11 & 1.19 \\
\hline $2006 / 01$ & 100.62 & 114.44 & 108.23 & 1.14 & 1.08 & 1.14 \\
\hline $2006 / 02$ & 101.46 & 131.92 & 110.61 & 1.30 & 1.09 & 1.32 \\
\hline $2006 / 03$ & 105.04 & 127.65 & 110.63 & 1.22 & 1.05 & 1.28 \\
\hline $2006 / 04$ & 104.49 & 125.64 & 116.74 & 1.20 & 1.12 & 1.26 \\
\hline $2007 / 01$ & 103.09 & 116.76 & 118.45 & 1.13 & 1.15 & 1.17 \\
\hline $2007 / 02$ & 102.38 & 130.80 & 120.39 & 1.28 & 1.18 & 1.31 \\
\hline $2007 / 03$ & 102.71 & 136.06 & 114.96 & 1.32 & 1.12 & 1.36 \\
\hline $2007 / 04$ & 104.89 & 137.65 & 107.78 & 1.31 & 1.03 & 1.38 \\
\hline $2008 / 01$ & 101.14 & 127.74 & 108.65 & 1.26 & 1.07 & 1.28 \\
\hline $2008 / 02$ & 104.32 & 139.32 & 111.93 & 1.34 & 1.07 & 1.39 \\
\hline $2008 / 03$ & 100.49 & 133.19 & 122.88 & 1.33 & 1.22 & 1.33 \\
\hline $2008 / 04$ & 98.91 & 130.56 & 127.15 & 1.32 & 1.29 & 1.31 \\
\hline $2009 / 01$ & 97.49 & 111.73 & 128.99 & 1.15 & 1.32 & 1.12 \\
\hline $2009 / 02$ & 94.86 & 113.01 & 129.31 & 1.19 & 1.36 & 1.13 \\
\hline $2009 / 03$ & 95.87 & 121.54 & 127.80 & 1.27 & 1.33 & 1.22 \\
\hline
\end{tabular}
trimestrales 2005-2015 


\begin{tabular}{|c|c|c|c|c|c|c|}
\hline \multirow{3}{*}{ Periodo } & \multirow{2}{*}{$\begin{array}{c}\text { Índice de ocupación } \\
\text { en el sector } \\
\text { manufacturero }\end{array}$} & Exportaciones totales & Importaciones totales & $F x$ & $F x, m$ & $Q x$ \\
\hline & & $\begin{array}{l}\text { Índice del volumen en } \\
\text { miles de pesos }\end{array}$ & $\begin{array}{l}\text { Índice del volumen en } \\
\text { miles de pesos }\end{array}$ & $Q x / T x$ & $Q m / T x$ & $(T x)(F x)$ \\
\hline & 1 & 2 & 3 & $4=2 / 1$ & $5=3 / 1$ & $6=((1)(4)) / 100$ \\
\hline $2010 / 01$ & 99.75 & 126.92 & 131.56 & 1.27 & 1.32 & 1.27 \\
\hline $2010 / 02$ & 99.09 & 141.18 & 128.48 & 1.42 & 1.30 & 1.41 \\
\hline $2010 / 03$ & 101.87 & 146.01 & 119.79 & 1.43 & 1.18 & 1.46 \\
\hline $2010 / 04$ & 99.90 & 148.84 & 114.87 & 1.49 & 1.15 & 1.49 \\
\hline 2011/01 & 99.74 & 142.34 & 116.80 & 1.43 & 1.17 & 1.42 \\
\hline $2011 / 03$ & 101.60 & 157.28 & 127.71 & 1.55 & 1.26 & 1.57 \\
\hline $2011 / 04$ & 103.67 & 172.21 & 130.03 & 1.66 & 1.25 & 1.72 \\
\hline $2012 / 01$ & 103.95 & 158.72 & 132.23 & 1.53 & 1.27 & 1.59 \\
\hline $2012 / 02$ & 104.35 & 176.44 & 134.59 & 1.69 & 1.29 & 1.76 \\
\hline $2012 / 03$ & 106.06 & 164.86 & 135.26 & 1.55 & 1.28 & 1.65 \\
\hline $2012 / 04$ & 106.43 & 165.46 & 142.41 & 1.55 & 1.34 & 1.65 \\
\hline 2013/01 & 105.95 & 146.33 & 139.59 & 1.38 & 1.32 & 1.46 \\
\hline $2013 / 02$ & 108.08 & 157.97 & 137.58 & 1.46 & 1.27 & 1.58 \\
\hline $2013 / 03$ & 109.98 & 162.99 & 130.15 & 1.48 & 1.18 & 1.63 \\
\hline 2013/04 & 111.93 & 164.24 & 127.05 & 1.47 & 1.14 & 1.64 \\
\hline $2014 / 01$ & 111.23 & 148.65 & 125.76 & 1.34 & 1.13 & 1.49 \\
\hline $2014 / 02$ & 110.78 & 165.78 & 130.85 & 1.50 & 1.18 & 1.66 \\
\hline $2014 / 03$ & 111.69 & 165.41 & 132.97 & 1.48 & 1.19 & 1.65 \\
\hline $2014 / 04$ & 112.27 & 173.65 & 135.41 & 1.55 & 1.21 & 1.74 \\
\hline $2015 / 01$ & 112.62 & 162.28 & 134.77 & 1.44 & 1.20 & 1.62 \\
\hline $2015 / 02$ & 113.61 & 183.21 & 135.55 & 1.61 & 1.19 & 1.83 \\
\hline $2015 / 03$ & 115.17 & 192.72 & 138.54 & 1.67 & 1.20 & 1.93 \\
\hline $2015 / 04$ & 117.44 & 192.94 & 145.08 & 1.64 & 1.24 & 1.93 \\
\hline
\end{tabular}

El índice de ocupación del sector manufacturero se obtuvo de INEGI (2016); los índices de cada capítulo se construyeron a partir de los datos proporcionados en miles de dólares y transformados a miles de pesos constantes a precios de la segunda quincena de 2010.

Fuente: INEGI (2016) y Banxico (2016).

En el Cuadro 5 se presenta el crecimiento de la capacidad importadora nacional, principalmente por el lado de las manufacturas mexicanas. Se puede observar que en el periodo que va de 2005 a 2015 , el crecimiento promedio del volumen de las exportaciones totales fue de 1.81 por ciento, mientras que el crecimiento del volumen de las importaciones totales fue de 0.93 por ciento. Se registra una productividad en el sector exportador de 1.14 por ciento, con una capacidad de trabajo aplicado en el sector exportador para generar importaciones de 0.58 por ciento y un índice de ocupación en el sector manufacturero del orden del 0.39 por ciento. Con los datos de las últimas columnas, también podemos dejar de lado la hipótesis 2), ya que vemos que la productividad del sector exportador $(F x)$ en el año 2015 fue de 1.75 y la productividad indirecta $(F x, m)$ de 0.61 por ciento. Por lo tanto, sólo nos queda introducirnos 
en el análisis de la hipótesis 3), que explica la reducción de las importaciones de los bienes que conforman la canasta salarial, como parte de una política que busca disminuir el déficit de la balanza exterior mediante menores importaciones, y con ello intentar reducir las presiones del tipo de cambio. Aunque esto vaya en detrimento de la población trabajadora mexicana.

\section{Conclusiones}

En este trabajo se muestra evidencia de la incapacidad de la política económica vigente de mantener una de las premisas fundamentales del patrón de acumulación neoliberal: la estabilidad cambiaria. Se documentan presiones devaluatorias de la moneda mexicana registradas entre los años 2005 y 2016, y lo limitado de la respuesta del gobierno mexicano para hacer frente a ellas. De acuerdo con los datos, al año 2016, la depreciación acumulada del peso fue del orden del 10.38 por ciento, alcanzando su punto máximo de depreciación en el mes de febrero, cuando el dólar se llegó a ubicar en los 19.03 pesos por dólar. Los mecanismos de los cuales el gobierno echó mano para hacer frente a esta situación resultaron insuficientes, al limitarse a: 1) la reducción de la acumulación de reservas internacionales, 2) a mecanismos de subasta de dólares sin precio mínimo, que no han dado una solución efectiva al problema, y 3) la reducción de las importaciones de los bienes que conforman la canasta salarial, que como se puede observar en el trabajo, atenta de manera considerable sobre las condiciones de consumo de los trabajadores asalariados mexicanos. Más en un contexto en el que no se tienen expectativas de que la economía mexicana comience con un proceso de sustitución de importaciones que le permita hacer frente a la disminución de las importaciones de bienes que conforman la canasta salarial.

\section{Bibliografía}

Banxico. (2015). Normalización de la Política Monetaria en Estados Unidos y sus implicaciones para las Economías Emergentes. XIII Conferencia Regional de Centroamérica, Panamá y República Dominicana, julio 24.

CEFP. (2016). Boletín: Situación del sector externo. http://www.cefp.gob.mx/publicaciones/ boleco/2016/becefp0062016.pdf, marzo de 2016.

CONASAMI. (2016). Datos estadísticos. http://www.conasami.gob.mx, junio de 2016.

CONEVAL-UNICEF. (2013). La niñez y la adolescencia en el contexto de la crisis económica global: el caso de México. México.

Guerrero, Diego. (2006). La explotación: trabajo y capital en España (1954-2001). Editorial El Viejo Topo.

Gurrieri, A. (1982). La obra de Prebisch en la Cepal. México: Fondo de Cultura Económica

La Jornada. (2012). "Preocupante aumento de la dependencia alimentaria de México". http://www. jornada.unam.mx/2014/04/21/politica/011n1pol

Martínez, J. G. (2005). Salarios, precios y productividad, una aproximación al valor de la fuerza de trabajo en México. Análisis Económico, 20(44), 63-91.

Marx, Carlos. (1973). Salario, precio y ganancia. En C. Marx y F. Engels Obras escogidas (186-232). Moscú: Progreso. 
Marx, Carlos. (1980). El Capital. Crítica de la Economía Política. México: Fondo de cultura Económica (Decimosexta reimpresión).

Moreno Brid, Juan Carlos y Luis Ángel Monroy Gómez Franco. (2015). El tipo de cambio real en periodos de crecimiento elevado y persistente: una taxonomía de la experiencia latinoamericana. En Estructura productiva y política macroeconómica. Enfoques heterodoxos desde América Latina (215-244). Santiago de Chile: CEPAL.

Pantaleón, Israel. (25 de agosto de 2016). México resentirá caída de precios del petróleo en 2016. 16 de abril de 2016, de Forbes Sitio web: http://www.forbes.com.mx/mexico-resentira-caida-deprecios-del-petroleo-en-2016/

Shaikh, A. (1984). Cuentas de ingreso nacional y categorías marxistas. Economía, teoría y práctica, 4, 3-58.

Valenzuela, J. C., \& Isacc, J. (1999). Explotación y despilfarro: análisis crítico de la economía mexicana. Plaza y Valdés, México DF.

Valle, Alejandro. (1991). Valor y precio: una forma de regulación del trabajo social. México: UNAM. 